\title{
Estimating the Mechanical Properties of Rock Masses
}

\author{
E.T. Brown Golder Associates Pty Ltd, Australia
}

\begin{abstract}
Reliably estimating the mechanical properties of discontinuous rock masses remains one of the greatest challenges faced in the discipline of rock mechanics. This paper discusses the development, uses and limitations of the Hoek-Brown empirical rock and rock mass strength criterion, some of the extensions made to the criterion by others, and associated methods of estimating rock mass deformabilities. Extreme care must be taken in extending the use of these approaches beyond reasonable limits. Modern methods of predicting the engineering responses of rocks and rock masses using advanced numerically-intensive methods provide a sound and promising basis for developing improved understandings of the engineering responses of rock masses and for making improved predictions of rock mass properties and performance.
\end{abstract}

\section{Introduction}

The Statutes of the International Society for Rock Mechanics (ISRM) state the following:

"... the field of rock mechanics is taken to include all studies relative to the physical and mechanical behaviour of rocks and rock masses and the application of this knowledge for the better understanding of geological processes and in the fields of engineering."

It follows, then, that the estimation of the mechanical properties of rock masses (for present purposes, their strengths and deformabilities) is at the core of our discipline, and that reliable estimates of these properties are required for almost any form of analysis used for the design of slopes, foundations and underground excavations in rock. Indeed, it is generally acknowledged that it was our inability to adequately determine these properties and the engineering responses of rock masses that provided at least part of the impetus for the founding of the ISRM in 1962. The Society's founding President, Leopold Müller, always emphasised the discontinuous nature of rock masses and said that the then existing methods of continuum mechanics and soil mechanics were inadequate for analysing rock engineering problems (Müller, 1964).

This general topic has always been the author's major interest since he commenced his Ph.D. studies under the supervision of Professor Hugh Trollope in 1964. As has been discussed elsewhere (Brown, 2004; 2007), Trollope was one of the first to insist on the need to treat both rocks and rock masses as discontinua and to develop a systematic theory of discontinua (Trollope, 1968). Until practically-useful numerical methods of evaluating the mechanical properties and responses of rocks and rock masses were developed relatively recently (see Section 6), it was a common practice to seek to estimate rock mass strengths and deformabilities using empirical correlations with rock mass classifications and rock material properties.

The author's name is associated with one of the most widely-used of these empirical approaches, the HoekBrown criterion (Hoek and Brown, 1980a; 1980b; 1988; 1997; Hoek et al., 1992; 2002). However, the author has not been directly associated with the changes that have been made to the criterion by Dr Hoek and his co-workers in the last decade, or with many of the extensions and refinements that have been made to the criterion by others. He is concerned that some of these developments may overlook the original purpose of the criterion, its basis and its fundamentally empirical nature. This paper provides the opportunity for the author to review the development of the Hoek-Brown criterion and to comment on other methods that have been used in engineering practice for estimating the mechanical properties of rock masses.

\section{The development of the Hoek-Brown criterion}

During the preparation of their book, Underground Excavations in Rock, in the late 1970s, Dr Evert Hoek and the author became acutely aware of the void that existed in our discipline through the lack of a reliable method for estimating the overall strengths of jointed or discontinuous rock masses. It was clear by that time 
that, if taken over other than narrow ranges of minor principal stresses, the peak compressive strength envelopes of intact rocks were curved. On the basis of a limited range of in situ tests and laboratory tests on models of jointed rock masses (John, 1962; 1970; Brown, 1970; Brown and Trollope, 1970; Jaeger, 1970; Ladanyi and Archambault, 1970) it was also becoming clear that the strength envelopes of jointed rock masses were similarly curved. The analysis of a range of available triaxial compression test data for intact rock and for the closely-jointed Panguna andesite tested by Jaeger (1970), and biaxial and triaxial test results for block-jointed models, led to the development of expressions for the non-linear peak strength envelopes of rocks and rock masses in terms of the major and minor principal stresses at peak strength (Hoek and Brown, 1980a; 1980b). Another important input into the development of the original expression was the plane stress application of Jaeger's single plane of weakness theory (Jaeger, 1960) in estimating the minimum strengths of rock masses containing several sets of mutually inclined joints having similar Mohr-Coulomb strength parameters as described by Hoek and Brown (1980a; 1980b) and Brown (2004). It was shown that for three or four sets of discontinuities which are mutually inclined at equal angles and have the same shear strengths, the strength, $\sigma_{1}-\sigma_{3}$, developed at a given value of confining pressure, $\sigma_{3}$, was essentially constant and independent of the orientations of the principal stresses.

The original expression of the empirical, non-linear, isotropic peak strength criterion for rock masses was given in total stress terms as:

$$
\sigma_{1}=\sigma_{3}+\sigma_{\mathrm{ci}}\left[m\left(\sigma_{3} / \sigma_{\mathrm{ci}}\right)+s\right]^{0.5}
$$

where $\sigma_{1}$ and $\sigma_{3}$ are the major and minor principal compressive stresses at peak strength, $\sigma_{\mathrm{ci}}$ is the uniaxial compressive strength of $50 \mathrm{~mm}$ diameter samples of the intact rock, and $m$ and $s$ are material parameters. For intact rock, $m$ and $s$ take their maximum values of $m_{i}$ and 1.0, respectively. In the original publications (Hoek and Brown, 1980a; 1980b), tables were given of values of $m_{i}$ for a range of rock types and of the equations of the peak strength envelopes for a more limited range of rock types of six rock mass qualities (including intact rock) expressed in terms of the CSIR or Bieniawski's Rock Mass Rating (RMR) (Bieniawski, 1976) and the NGI or Barton's Q factor (Barton et al., 1974). Priest and Brown (1983) showed that it was possible to express the relations between $m, s$ and RMR by simple exponential relationships that were used in subsequent versions of the criterion. It was soon also realised that it was necessary to distinguish between disturbed and undisturbed or interlocked rock masses, and two sets of equations of the type proposed by Priest and Brown (1983) were developed (Hoek and Brown, 1988).

The original peak strength criterion (Equation (1)) included a square root term with a power of 0.5 instead of the variable value, $a$, used in the most recent forms of the criterion (Equation (2)). It is interesting to note that a similar square root term appeared in peak strength envelopes for intact rock and other brittle materials that had been developed mainly in the 1960s using Griffith crack theory (Cook, 1965; Hoek, 1968; Jaeger and Cook, 1969). Recently, Zuo et al. (2008) used Griffith crack and fracture mechanics approaches to derive a non-linear peak strength criterion that is mathematically identical to Equation (1) with $s=1$. It is important to note that in the extensive data set for intact rocks analysed by Hoek and Brown (1980a) in developing the criterion, values of $\sigma_{\mathrm{ci}}$ varied from $40 \mathrm{MPa}$ (for a British sandstone) to $580 \mathrm{MPa}$ (for a South African chert dyke). It is for this reason that the criterion in which $a=0.5$ was often said to apply to "hard" rocks.

The subsequent development of the criterion has been outlined by Hoek (2007) in the following terms:

"The method was modified over the years in order to meet the needs of users who were applying it to problems that were not considered when the original criterion was developed (Hoek, 1983; Hoek and Brown, 1988). The application of the method to very poor quality rock masses required further changes (Hoek et al., 1992) and, eventually, the development of a new classification called the Geological Strength Index (Hoek, 1994; Hoek et al., 1995; 1998; Hoek and Brown, 1997; Marinos and Hoek, 2001). A major revision was carried out in 2002 in order to smooth out the curves, necessary for the application of the criterion in numerical models, and to update the methods for estimating Mohr-Coulomb parameters (Hoek et al., 2002). A related modification for estimating the deformation modulus was made by Hoek and Diederichs (2006)."

In respect of this last comment, it is important to note that, although the Hoek-Brown criterion was a peak compressive strength criterion, from the very beginning (Hoek and Brown, 1980a) methods of estimating 
rock mass deformability were also considered (see Section 5). A more detailed summary of the history of the development of the criterion is given by Hoek and Marinos (2007).

The 2002 or generalised Hoek-Brown criterion (Hoek et al., 2002) is expressed in effective stress terms as:

$$
\sigma_{1}{ }^{\prime}=\sigma_{3}{ }^{\prime}+\sigma_{\mathrm{ci}}\left[m_{b}\left(\sigma_{3}{ }^{\prime} / \sigma_{\mathrm{ci}}\right)+s\right]^{a}
$$

where $\sigma_{1}{ }^{\prime}$ and $\sigma_{3}{ }^{\prime}$ are the major and minor principal effective stresses at peak strength, $m_{b}$ is introduced as the value of the constant $m$ for the rock mass, and the value of the index, $a$, is given by:

$$
a=1 / 2+1 / 6\left(e^{-G S I / 15}-e^{-20 / 3}\right)
$$

where GSI is the value of the Geological Strength Index introduced from 1994 as discussed previously. According to Equation (3), as GSI $\rightarrow 0$, the maximum possible value of $a$ is about 0.65 , a value found by Pan and Hudson (1988) to apply to the Melbourne mudstone tested by Johnston and Chiu (1984), and by Medhurst and Brown (1998) for coal from the Moura mine, Queensland. The parameters $m_{b}$ and $s$ are given by the expressions:

$$
m_{b}=m_{i} \exp \left(\frac{G S I-100}{28-14 D}\right)
$$

and

$$
s=\exp \left(\frac{G S I-100}{9-3 D}\right)
$$

In Equations (4) and (5), $D$ is a factor which varies with the degree of disturbance due to blast damage and stress relaxation. It varies from zero for undisturbed in situ rock masses to one for highly disturbed rock masses. Guidelines for the selection of $D$ are given by Hoek et al. (2002) and Hoek (2007). As will be discussed in Sections 3.3 and 5, the disturbance factor, $D$, should be applied only to the damaged zone and not to the entire rock mass.

The uniaxial compressive strength of the rock mass is obtained by setting $\sigma_{3}{ }^{\prime}$ to zero in Equation (2), giving:

$$
\sigma_{\mathrm{crm}}=\sigma_{\mathrm{ci} .} S^{a}
$$

By putting $\sigma_{1}{ }^{\prime}=\sigma_{3}{ }^{\prime}=\sigma_{\mathrm{trm}}$ in Equation (2), the uniaxial tensile strength of the rock mass is given as:

$$
\sigma_{\mathrm{trm}}=-s \sigma_{\mathrm{ci}} / m_{b}
$$

with compression being positive.

\section{Uses, abuses and limitations of the Hoek-Brown criterion}

\subsection{General ranges of applicability and application of the criterion}

The reason for proposing the criterion given by Equations (1) and (2) was to provide a means of estimating the peak strengths of large-scale rock masses containing several sets of discontinuities. Over the years, several versions of the diagram shown in Figure 1 have been used to explain the range of applicability of the criterion. This figure indicates that the criterion should not be used in cases where there are only one or two sets of discontinuities, and that the form of the criterion for intact rock should be used for small samples or for massive rock containing no discontinuities. As will be discussed in Section 3.2, laboratory and field investigations carried out over the last decade or so have shown that a modified version of the criterion for intact rock should be used in predicting the onset of brittle fracture and the depth of brittle or spalling failure around underground excavations in massive, brittle rock (Martin et al., 1999; Kaiser et al., 2000; Cai et al., 2004a; Kaiser, 2006; Diederichs et al., 2007).

It should also be noted that the increasing sample size in the caption to Figure 1, refers to the introduction of more discontinuities with increasing sample size, not to the effect of increasing sample size on the strength of the intact rock itself. Hoek and Brown (1980a) analysed uniaxial compression test data then available for a range of rock types and proposed a power law with a constant index to describe the influence of an increase 
in sample diameter on the uniaxial compressive strength of intact rock samples. It was suggested that the decreasing compressive strength observed with increasing sample size reflects the effect of the increasing numbers of micro-defects likely to be contained within larger samples. Recently, Yoshinaka et al. (2008) found that the form of the relationship proposed by Hoek and Brown (1980a) applies to a wider range of data than that available to Hoek and Brown (1980a), but with a variable index which depends on rock type.

The criterion was intended for use in making approximate estimates of rock mass strengths for use in preliminary studies of rock engineering projects for which only limited ranges of site characterisation and test data were available. As time went by, the criterion became incorporated into more sophisticated methods of analysis and used for final design to the extent that it is now probably the most widely-used and referred to rock mass strength criterion in modern rock engineering. It has even been described as "famous" in one recent paper (Maghous et al., 2008). As has been indicated, the original interest of Hoek and Brown (1980a; 1980b) was with underground excavations. The criterion was quickly applied to large slopes which remain one of its major applications (Hoek and Brown, 1997; Hoek and Karzulovic, 2000; Li et al., 2008). The criterion has also been widely used to estimate rock mass strengths for use in the design of dam (Fell et al., 2005; Marley et al., 2007; Alemdag et al., 2008; Brown and Marley, 2008) and building foundations, and incorporated into bearing capacity calculation methods (Serrano et al., 2000; Merifield et al., 2006).

In the author's opinion, there is a limit to the range of GSI values over which the criterion may be applied with confidence. As will be discussed further in Section 3.2, care must be exercised when dealing with brittle fracture in strong, massive rocks with high GSI values of $70-75$ or more. Similarly, special care must be exercised at low values of GSI of below about 30, and in tectonically disturbed, and heterogeneous and lithologically varied rocks such as flysch (Marinos and Hoek, 2001; Marinos et al., 2006; 2007). The estimation of GSI values in these latter cases is a task for experienced specialists having detailed knowledge of the rocks concerned. The generalised Hoek-Brown criterion may not apply for weak rocks with, say, $\sigma_{\mathrm{ci}}<15 \mathrm{MPa}$, because it has been found that, at these low strengths, the index, $a$, can be greater than the maximum value of about 0.65 given by Equation (3) and can approach one, a value that is usually taken to apply to soil (Mostyn and Douglas, 2000; Douglas and Mostyn, 2004; Carvalho et al., 2007; Carter et al., 2007; 2008).

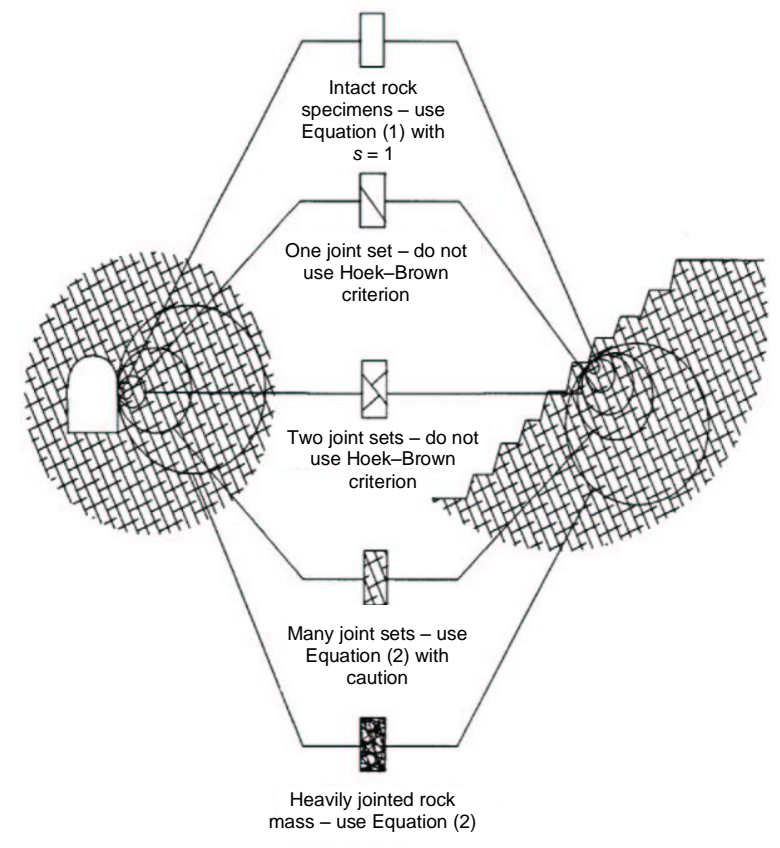

Figure 1 Idealised diagram showing the transition from intact to a heavily joined rock mass with increasing sample size (after Hoek, 2007) 


\subsection{Brittle fracture near underground excavations}

Figure 2 shows a diagram developed by Hoek et al. (1995), Martin et al. (1999) and Kaiser et al. (2000), illustrating a generalised relationship between the degree of natural fracturing of a rock mass as measured by the GSI, the level of the applied stress with respect to the compressive strength of the intact rock, and the likely modes of failure around a tunnel. Figure 2 postulates that, for the intermediate and high stress cases, brittle fracture of intact rock occurs around the excavation boundary in all but the highly fractured or low GSI case. Of the cases illustrated in Figure 2, the empirical Hoek-Brown isotropic strength criterion is best applied to the highly fractured, high stress case. Experience has shown that if the peak strength criterion is applied where brittle fracture as opposed to general shearing of the rock mass occurs, the size of the failure zone around the excavation can be over-estimated. Diederichs et al. (2007) suggest that the application of Equations (2) to (5) is of limited reliability when used for undisturbed $(D=0)$ hard rock masses with GSI > 75 , and may be of mixed success for GSI $=65$ to 75 .

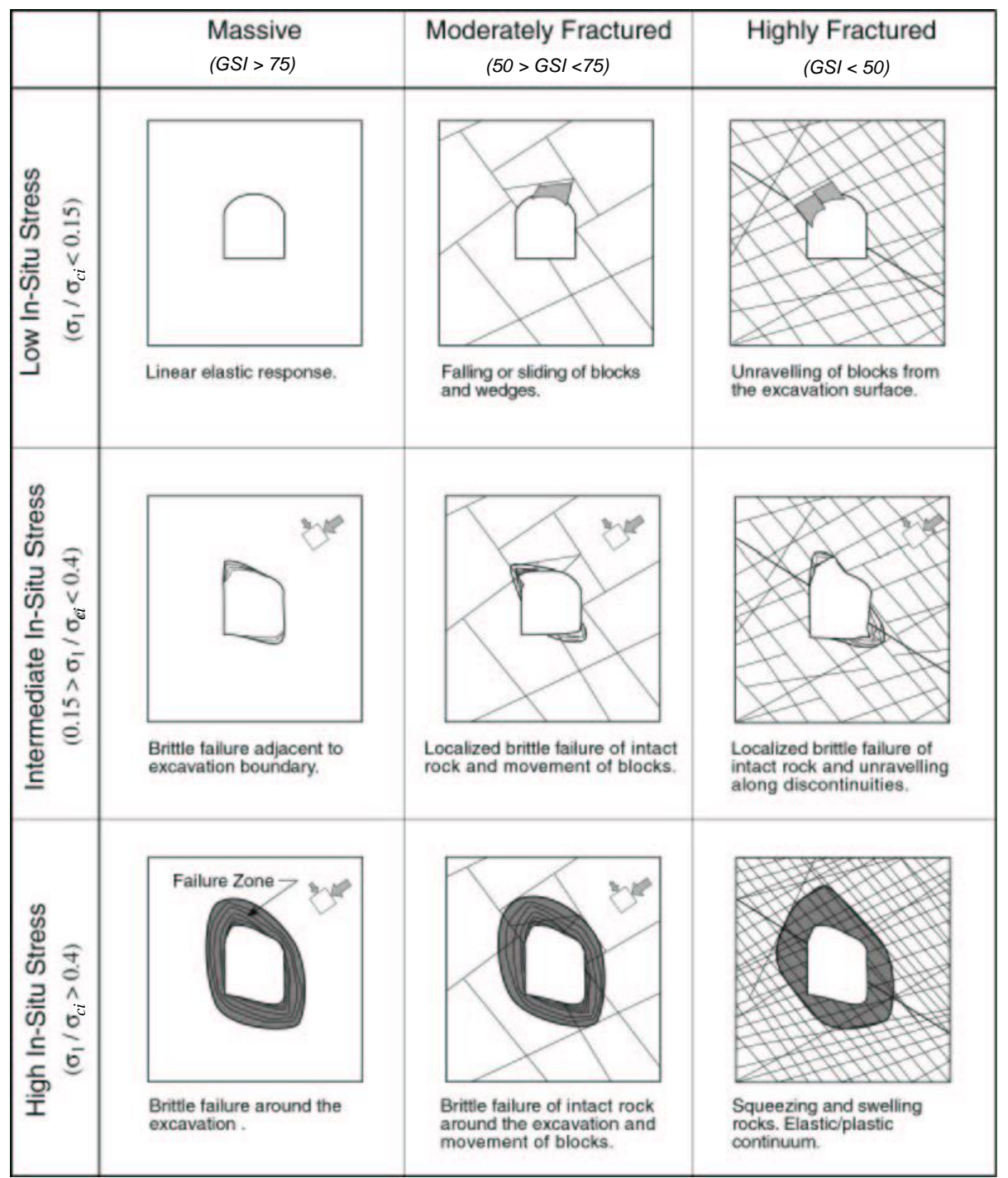

Figure 2 Tunnel instability and brittle failure as a function of GSI and the ratio of the maximum far-field stress, $\sigma_{1}$, to the unconfined compressive strength, $\sigma_{\mathrm{ci}}$ (after Kaiser et al., 2000)

An instructive and practically-useful interpretation of the Hoek-Brown criterion for brittle failure at low confining pressures has been developed by Martin (1997) and others (Martin et al., 1999; Kaiser et al., 2000; Diederichs et al., 2004). Martin (1997) studied the laboratory and field behaviour of Lac du Bonnet granite from the Underground Research Laboratory (URL) site, Manitoba, Canada. He found that the start of the fracture or failure process began with the initiation of damage caused by small cracks growing in the direction of the maximum applied load. 
For unconfined Lac du Bonnet granite, this occurred at an applied stress of 0.3 to $0.4 \sigma_{\mathrm{ci}}$ where $\sigma_{\mathrm{ci}}$ is the uniaxial compressive strength of the intact rock. As the load increased, these stable cracks continued to accumulate. Eventually, when the sample contained a sufficient density of cracks, they started to interact and an unstable cracking process involving sliding was initiated. The stress level at which this unstable cracking process is initiated is referred to as the 'long-term strength' of the rock, $\sigma_{\mathrm{cd}}$. Martin (1997) argued that, in terms of the Coulombic concepts of cohesion and friction, the mobilised strength to this stage is cohesive. After the stress $\sigma_{\mathrm{cd}}$ has been reached, cohesion is lost and frictional strength is mobilised. In any event, the author considers that the Coulombic concept of summed 'cohesive' and 'frictional' components of peak strength, is not applicable to the progressive accumulation of fracture damage that has been observed to occur in well-conducted compression tests on 'hard' rocks (Wawersik and Fairhurst, 1970; Martin, 1997).

Martin (1997) determined the laboratory peak, long-term and crack initiation strengths for the Lac du Bonnet granite. He was able to fit Hoek-Brown envelopes to these curves, although the laboratory crack initiation curve was found to be a straight line on $\sigma_{1}$ versus $\sigma_{3}$ axes. Subsequently, in a field experiment carried out at the URL site, the initiation of cracks around a tunnel excavated in the Lac du Bonnet granite was recorded using microseismic emissions. These data corresponded well with the laboratory crack initiation data. It was found that crack initiation at an approximately constant deviatoric stress, $\left(\sigma_{1}-\sigma_{3}\right)$, could be well represented by the Hoek-Brown criterion with $m_{b}=0$ and $s=0.11$ (Martin et al., 1999).

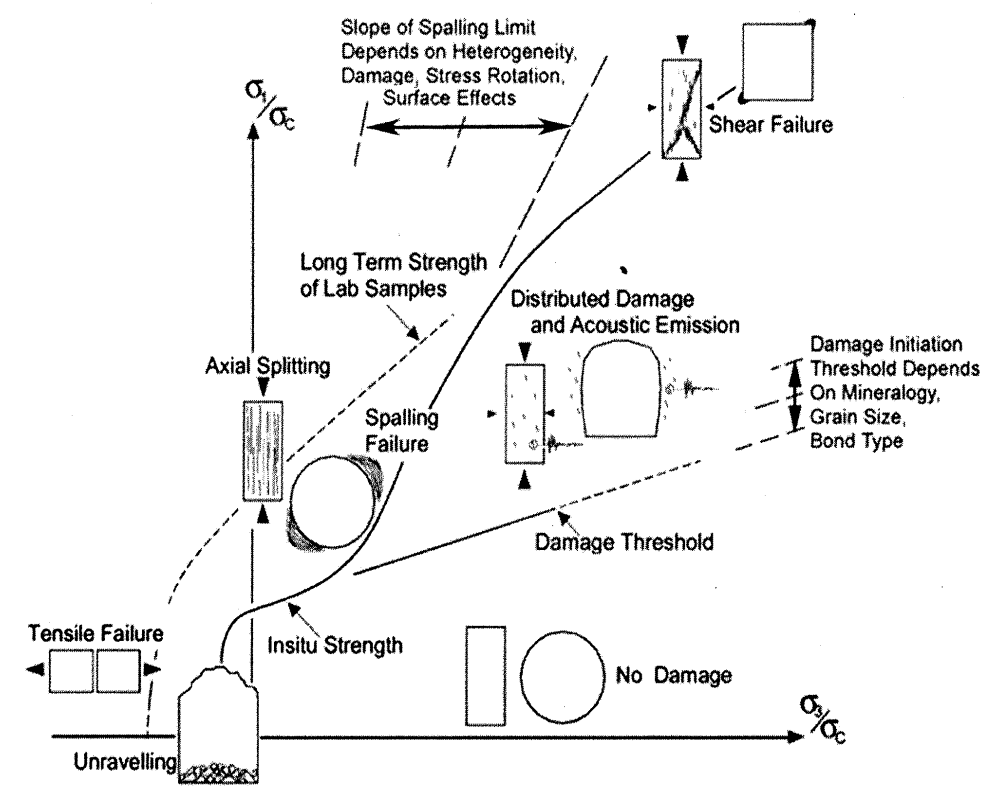

Figure 3 Modes of rock damage and failure and the composite in situ strength envelope for hard rock (Diederichs et al., 2004; 2007)

Figure 3 shows a representation in normalised principal stress space of the fracture initiation, fracture extension, damage accumulation and shear failure envelopes, and the corresponding manifestations of rock mass failure around underground excavations. It will be noted that the composite in situ strength curve for the rock mass does not follow the peak Hoek-Brown strength curve, but the curve given by the solid black line. The several domains identified in Figure 3 may be defined by linear stress boundaries expressed by a generic form of the various 'failure' criteria as:

$$
\sigma_{1}=\mathrm{A} \sigma_{3}+\mathrm{B} \sigma_{\mathrm{ci}}
$$

Using this expression, the threshold for crack initiation and the onset of dispersed microseismic activity indicative of microscopic rock damage, is defined by $\mathrm{A}=1-1.5, \mathrm{~B}=0.4-0.5$. This approximates the maximum deviator stress criterion of Martin et al. (1999). It should be noted that the location of the damage threshold envelope depends on the mineralogy, grain size and bonding of the rock. The term $\mathrm{B} \sigma_{\mathrm{ci}}$ in Equation (8) is effectively the uniaxial compressive strength of the rock mass, UCS, which can be used to scale other strength relations. A second threshold, described by $\mathrm{A}=2$, is identified with the onset of 
systematic fabric damage accumulation, and is represented by a transition from dispersed microseismic events to localised seismic clusters. The third threshold, given by $A=3-4$, represents the conventional peak strength of the rock mass, corresponding to the interaction of damage zones and the localisation of extension fractures into shear zones. Finally, a fourth threshold with $A=0, B=10-20$, applies close to excavation boundaries, under conditions where surface conditions tend to promote spalling.

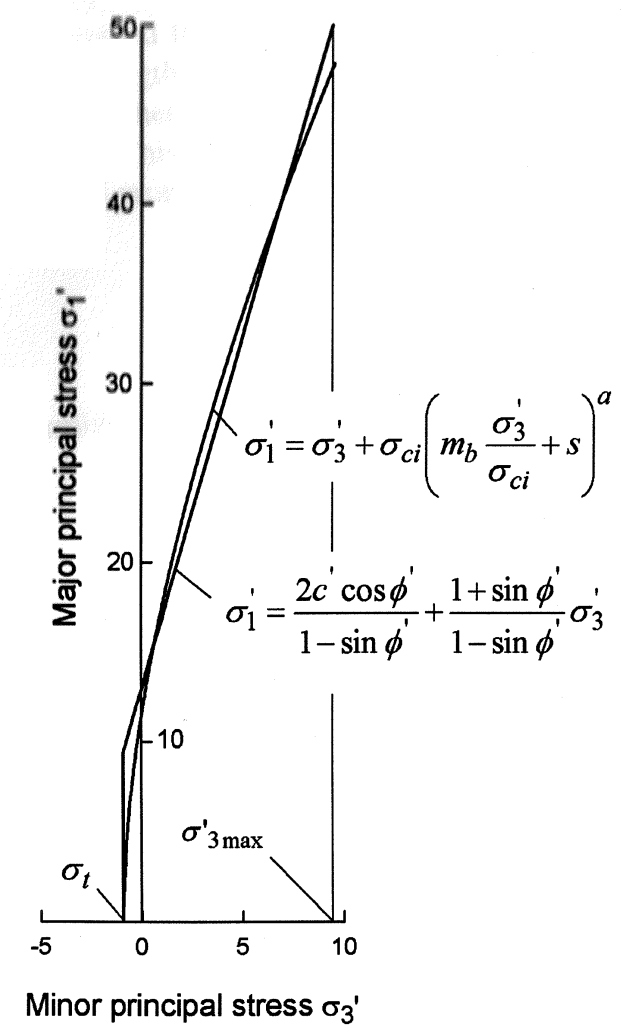

Figure 4 Relationships between major and minor principal effective stresses for the Hoek-Brown and equivalent Mohr-Coulomb criteria (Hoek, 2007)

\subsection{Determination of equivalent Mohr-Coulomb shear strength parameters}

Because of the methods of analysis used in some applications, particularly slope stability analysis, and the requirements of the associated software packages, equivalent Mohr-Coulomb shear strength parameters rather than relationships between the peak principal effective stresses given by Equation (2) are often required. As illustrated in Figure 4, it is possible to estimate these parameters by fitting a straight line to the Hoek-Brown envelope over a limited range of $\sigma_{3}$ '. Deriving exact analytical expressions for the equivalent Mohr-Coulomb parameters at a given effective normal stress has proven to be a challenging task (Hoek and Brown, 1997; Hoek et al., 2002; Priest, 2005; Hoek, 2007). The software package, RocLab (Rocscience, 2007) allows equivalent Mohr-Coulomb parameters to be calculated for given input data, selected applications and maximum values of the minor principal stress.

The author would advise users against seeking to apply RocLab too automatically without thinking clearly about the range of effective normal stress that is likely to apply in the case being considered. If too wide a range of $\sigma_{3}$ ' is used, equivalent effective cohesion values that are too high, and equivalent effective friction angles that are too low, will result. Errors can also be made by an overly literal interpretation of the guidelines given by Hoek et al. (2002) and Hoek (2007) for the selection of values of the disturbance factor, $D$, resulting in the use of values that are too high, or are applied to the entire rock mass rather than to just the disturbed zone of, perhaps, a few metres. As noted by Hoek (2007), applying $D$ to the entire rock mass can produce misleading and unnecessarily pessimistic results. In any event, care must be taken to ensure that the estimated shear strengths of rock masses are not below those of the weakest constituent discontinuities. 


\subsection{Influence of the intermediate principal stress}

It will be noted that the original and generalised forms of the Hoek-Brown criterion given by Equations (1) and (2) are expressed in terms of the major and minor principal stresses and do not include the intermediate principal stress, $\sigma_{2}$, except insofar as $\sigma_{2}=\sigma_{3}$ in the triaxial compression test. At the time the original criterion was formulated, a number of investigators had shown that, when it was not equal to $\sigma_{3}$, increasing the intermediate principal stress produced small but measurable increases in the peak strengths of intact rocks tested in true multi-axial compression. However, Hoek and Brown (1980a) argued that while it was a simplification to ignore the influence of $\sigma_{2}$ on rock material strength, to do so was justifiable in terms of the objective of keeping the criterion as simple as possible. They also had doubts about the adequacy of some of the testing techniques that had yielded apparently significant influences of $\sigma_{2}$. Recently, this view has been confirmed by numerical experiments carried out by Cai (2008a).

The use of a plane stress analysis in which the Jaeger single plane of weakness theory was applied in several parts to estimate the strength of a multiply jointed rock mass was referred to in Section 2. Analyses of this type would suggest that the value of $\sigma_{2}$ could be expected to have little or no influence. However, in a fully three-dimensional (3D) solution, Amadei (1988) showed that $\sigma_{2}$ can have a considerable influence on the peak strength of a regularly jointed rock mass. When $\sigma_{2}$ acts parallel to the plane of a major discontinuity, it will have no effect on the shear or normal stresses on that plane. But when $\sigma_{2}$ is inclined to any potential shear plane in the rock mass, it will influence the stresses on that plane, and so can be expected to influence the observed strength (Brown, 1984). Large-scale tests on jointed samples carried out by Reik and Zacas (1978) showed that this was, indeed, the case. Serrano et al. (2007) proposed a form of the generalised Hoek-Brown criterion that includes $\sigma_{2}$ as well as two new parameters, $\alpha$ and $\eta$, whose values are established by fitting curves to test results for intact rock. The author has doubts about the applicability of the results obtained to discontinuous rock masses which is the case of most practical concern.

As will be discussed in Section 4.2, the use of the Hoek-Brown criterion as a yield criterion in elasto-plastic analyses has led to the development of a range of criteria that include the intermediate principal stress in expressions that are usually given in terms of the principal stress invariants and the invariants of the deviator stress tensor (Pan and Hudson, 1988; Cundall et al., 2003; Priest, 2005; Benz et al., 2008; Clausen and Damkilde, 2008).

\subsection{Compressive strength anisotropy}

The Hoek-Brown criterion is intended for use with rocks and rock masses that have essentially isotropic strengths. It should not be used in cases in which the strength of the rock or the rock mass is likely to be dominated by one or two sets of discontinuities, or by a major through-going structure such as a fault or shear zone. However, Hoek and Brown (1980a; 1980b) did show how the parameters $m$ and $s$ in the original version of the criterion could be adjusted empirically to give good fits to the variation with orientation of the peak triaxial compression strengths of a range of anisotropic rocks. It is not recommended that the empirical parameters derived by Hoek and Brown (1980a; 1980b) be applied without carrying out a carefully designed and conducted testing program. Subsequently, a number of other authors have attempted to develop anisotropic strength versions of the criterion. One of the most useful of these attempts is considered to be that by Saroglou and Tsiambaos (2008) who use Londe's dimensionless formulation of the Hoek-Brown criterion (Londe, 1988) to be discussed in Section 4.1. Following Hoek and Brown (1980a; 1980b), Saroglou and Tsiambaos (2008) took the uniaxial compressive strength of the intact anisotropic rock, $\sigma_{\mathrm{ci}}$, and the parameter, $m_{i}$, to be the values obtained from tests carried out with the plane of anisotropy perpendicular to the axial loading or $\sigma_{1}$ direction. It should be recognised, however, that modifications such as these, and some others, represent departures from the original purposes and simplicity of the criterion.

\section{$4 \quad$ Adaptations and extensions}

Possibly because a lack of other established approaches, a number of authors have developed adaptations, refinements or extensions to the Hoek-Brown criterion in addition to those with which Hoek and Brown themselves have been associated. Many of these contributions attempt to produce what the author considers to be unjustified or unnecessary refinement, precision and complexity into the process of estimating rock and rock mass properties. Nevertheless, some important contributions to knowledge and the available techniques 
have been made in the process. Some of those relating to brittle fracture initiation and development, the influence of the intermediate principal stress, and anisotropy have been discussed in Section 3. A small number of other contributions will be outlined here.

\subsection{Londe's dimensionless formulation}

The initial difficulty experienced in determining equivalent Mohr-Coulomb shear strength parameters for the non-linear Hoek-Brown strength criterion expressed in terms of principal stresses was noted in Section 3.3. In commenting on a solution proposed by Ucar (1986), Londe (1988) developed an elegant solution to the problem which has since found significant application (Carranza-Torres and Fairhurst, 1999; CarranzaTorres, 2004; Saroglou and Tsiambaos, 2008). Londe (1988) began by dividing each term in the effective stress form of Equation (1) by $m \sigma_{\mathrm{ci}}$ and rearranging to produce the dimensionless equation:

$$
\mathrm{N}_{1}-\mathrm{N}_{3}=\mathrm{N}_{3}{ }^{0.5}
$$

where:

$$
\mathrm{N}_{1}=\left(\sigma_{1}{ }^{\prime} / m \sigma_{\mathrm{ci}}\right)+s / m^{2}
$$

and:

$$
\mathrm{N}_{3}=\left(\sigma_{3}{ }^{\prime} / m \sigma_{\mathrm{ci}}\right)+s / m^{2}
$$

A Mohr's circle constructed using $\mathrm{N}_{1}$ and $\mathrm{N}_{3}$ instead of the corresponding values of $\sigma_{1}{ }^{\prime}$ and $\sigma_{3}{ }^{\prime}$, depends on only one parameter, $d=\mathrm{N}_{1}-\mathrm{N}_{3}$, and so is unique for any combination of values of $m, s$ and $\sigma_{\mathrm{ci}}$. The inclination of the tangent to the circle at a dimensionless point $(\mathrm{N}, \mathrm{T})$ is given by $\sin \varphi^{\prime}=(4 d+1)^{-1}$, and the corresponding value of the equivalent cohesion, $\mathrm{c}^{\prime}$, can be determined analytically.

Carranza-Torres and Fairhurst (1999) used Londe's transformation (Equation (9)) and similarly scaled the internal support pressure and the far-field stresses in an analysis of the elasto-plastic responses of cylindrical and spherical underground excavations in hydrostatic stress fields. More recently, Carranza-Torres (2004) used Londe's approach to express the generalised form of the Hoek-Brown criterion (Equation (2)) in a tractable dimensionless form as:

$$
S_{1}=S_{3}+\eta S_{3}{ }^{a}
$$

where:

$$
S_{i}=\frac{\sigma_{i}}{m_{b} \sigma_{c i}}+\frac{s}{m_{b}{ }^{2}}
$$

and:

$$
\eta=m_{b}^{((2 a-1) a)}
$$

Note that for $a=0.5$ as in Equation (1), $\eta=1$, and Equation (13) reduces to the form of Equations (10) and (11). Carranza-Torres (2004) showed that the peak strengths measured in a range of triaxial compression tests on several hard rock types, including some of those analysed originally by Hoek and Brown (1980a; $1980 \mathrm{~b}$ ), plotted as straight lines on transformed principal stress axes, $S_{1}$ and $S_{3}$, for the case, $a=0.5$. Saroglou and Tsiambaos (2008) used a similar approach in analysing anisotropic rock strength data although, in their case, the resulting $S_{1}$ versus $S_{3}$ curve was not linear.

\subsection{High GSI and intact rock strength extensions}

The need to modify the generalised Hoek-Brown criterion for the high GSI case to allow for brittle fracture or spalling in hard rock was discussed in Section 3.2. In this case, the rock mass behaviour is controlled by the rock matrix, with strength failure involving the creation of new fractures, as opposed to the inter-block shear failure occurring in the mid-range of GSI for which the Hoek-Brown criterion has been found to apply reasonably well (Cai et al., 2004b). In a recent series of papers, Carter et al. (2007; 2008) and Diederichs et al. (2007) have extended the approach outlined in Section 3.2 to provide modified Hoek-Brown envelopes for the brittle or spalling case, and transition functions for the range between the operation of the generalised Hoek-Brown criterion and the spalling criterion. 
The procedure developed by Carter et al. $(2007 ; 2008)$ and Diederichs et al. (2007) is too complex to discuss in detail here. They suggest that an onset of systematic cracking or spalling initiation threshold curve can be defined by the Hoek-Brown criterion using the spalling parameters, $a_{S P}, m_{S P}$ and $s_{S P}$, for which expressions are given. This curve will generally apply for GSI $>65$ and $m_{i} \gg 15$, but both GSI and $m_{i}$ need to be considered in establishing the ranges of application of the spalling criterion. For example, spalling may develop in moderately jointed (say, GSI $>65)$ and high $m_{i}\left(m_{i}>20\right)$ rocks, or in more sparsely jointed rocks (say, GSI > 75) having an intermediate value of $m_{i}\left(m_{i}>15\right)$. Because initiating spalling cracks can propagate only under low confinement, a limit is proposed to establish a transition between spalling behaviour at low confinement and a shear strength that is closer to the long-term strength limit for the intact rock at higher confinements as defined in Section 3.2. This residual spalling limit is approximated using $a_{S P}=0.75, s_{S P}=0$ and $m_{r e s} \approx m_{i} / 3$ (Diederichs et al., 2007; Carter et al., 2008). Transitional functions between the conventional GSI-based Hoek-Brown parameters and the spalling parameters are proposed with both GSI and $m_{i}$ being used as indicators of spalling potential.

Carter et al. (2007; 2008) and Diederichs et al. (2007) estimate $m_{i}$ as being approximately equal to $\sigma_{\mathrm{c}} / \mathrm{T}$ where $\mathrm{T}$ is a "reliable estimate" of the uniaxial tensile strength of the intact rock. Of course, a series of wellconducted triaxial compression tests provides the most reliable way of establishing a value of $m_{i}$ for a given rock. In the past, where it has not proven possible to have these tests carried out, for one reason or another, the author has used this correlation for making preliminary estimates of the value of $m_{i}$, with $\mathrm{T}$ being estimated from Brazilian test results, for example. As noted in Section 2, in a recent analysis based on Griffith crack and linear elastic fracture mechanics principles, Zuo et al. (2008) obtained a peak strength equation that is mathematically identical to the original form of the Hoek-Brown criterion for intact rock with $m_{i}=(\mu / \kappa) .\left(\sigma_{\mathrm{c} i} / \mathrm{T}\right)$, where $\mu$ is the coefficient of friction on initially closed, sliding Griffith cracks, and $\kappa$ is a mixed-mode fracture coefficient. For the maximum energy release rate criterion, $\kappa=1$, and is close to unity for other criteria, so that if $\mu \approx 1, \mathrm{~m}_{\mathrm{i}} \approx \sigma_{\mathrm{c} i} / \mathrm{T}$.

\subsection{Low GSI and intact rock strength extensions}

As was noted in Section 3.1, there are also lower limits of GSI and $\sigma_{\mathrm{ci}}$ values below which the Hoek-Brown criterion should be applied with extreme caution or not at all. A number of authors have proposed modifications of, or replacements for, the Hoek-Brown criterion in the low material strength, low GSI range (Johnston and Chiu, 1984; Mostyn and Douglas, 2000; Douglas and Mostyn, 2004; Carter et al., 2007; 2008; Carvalho et al., 2007). There are two major difficulties in seeking to apply the classical (Equation (1)) or generalised (Equation (2)) forms of the Hoek-Brown criterion to low GSI and/or low intact rock strength rock masses. Firstly, in these cases, generally as a result of weathering or alteration of the rock material, discrete discontinuities may not be as well expressed as they are in the mid-GSI range where they are taken control rock mass behaviour and the Hoek-Brown criterion is found to apply reasonably well. Secondly, as was noted in Section 3.1, as $\sigma_{\mathrm{ci}}$ decreases, the index, $a$, in Equation (2), can become greater than the maximum value of about 0.65 given by Equation (3), and can approach one, a value that is usually taken to apply to soils.

Mostyn and Douglas (2000) analysed a range of test results and found that values of $a$ of significantly greater than 0.65 could apply, that the corresponding values of $m_{i}$ did not correspond to those in tables given by Hoek and Brown (1980a; 1980b; 1997), and that $a$ and $m_{i}$ were not independent parameters. This finding has some similarities with the observation of Carvalho et al. (2007) and Carter et al. $(2007 ; 2008)$ that, as the generalised form of the Hoek-Brown criterion is linearised by letting $a \rightarrow 1$, the values of the parameter $m$ required to produce equivalence with the Hoek-Brown criterion are in the order of $m_{i} / 3$ where $m_{i}$ is determined using $a=0.5$. However, care must be exercised in reaching conclusions about relationships between $a$ and $m_{i}$, and the validity of particular $m_{i}$ values, because the curvature of peak $\sigma_{1}$ versus $\sigma_{3}$ envelopes can be greatly influenced by the range of $\sigma_{3}$ over which the envelope is plotted. Lower ranges of $\sigma_{3}$ are likely to give more linear envelopes and, therefore, higher values of $a$ and lower values of $m_{i}$. The author suspects that some critics of the criterion may not have taken this factor fully into account.

Carvalho et al. (2007) and Carter et al. $(2007 ; 2008)$ also propose transition values of $a, s$, and $m_{b}$ for use in the range between full linearisation $(a=1)$ and the generalised Hoek-Brown criterion with $\sigma_{\mathrm{ci}}$ as the controlling variable up to values of 10-15 MPa. Figure 5 shows this transition function and that for the high GSI and $\sigma_{\mathrm{ci}}$ range discussed in Section 4.2, plotted on normalised rock mass strength $\left(\sigma_{\mathrm{crm}} / \sigma_{\mathrm{ci}}\right)$ versus GSI 
axes. Note that in this figure taken from the paper by Carter et al. (2008), $\mathrm{UCS}_{\mathrm{rm}}=\sigma_{\mathrm{crm}}, \mathrm{UCS}_{\mathrm{i}}=\sigma_{\mathrm{ci}}$, and the spalling transition threshold is set at a typical value of UCS $=0.45 \sigma_{\mathrm{ci}}$. The spalling transition is represented by solid lines and the weak rock transition by dashed lines.

In the author's opinion, attempts to apply the Hoek-Brown criterion to low GSI and/or low $\sigma_{c i}$ cases extend the criterion outside the range of applicability of the assumptions and data on which it was based. It is not unexpected, therefore, that a number of authors have found difficulty in applying the criterion in these cases. Furthermore, the author doubts the wisdom of seeking to modify or extend the generalised criterion to forcefit the criterion to cases that lie outside the ranges of GSI and $\sigma_{c i}$ for which it has been found to provide useful results. In these cases, it may be more productive to use rock and rock mass strength criteria that have been developed specifically for the range of behaviour that is being described.

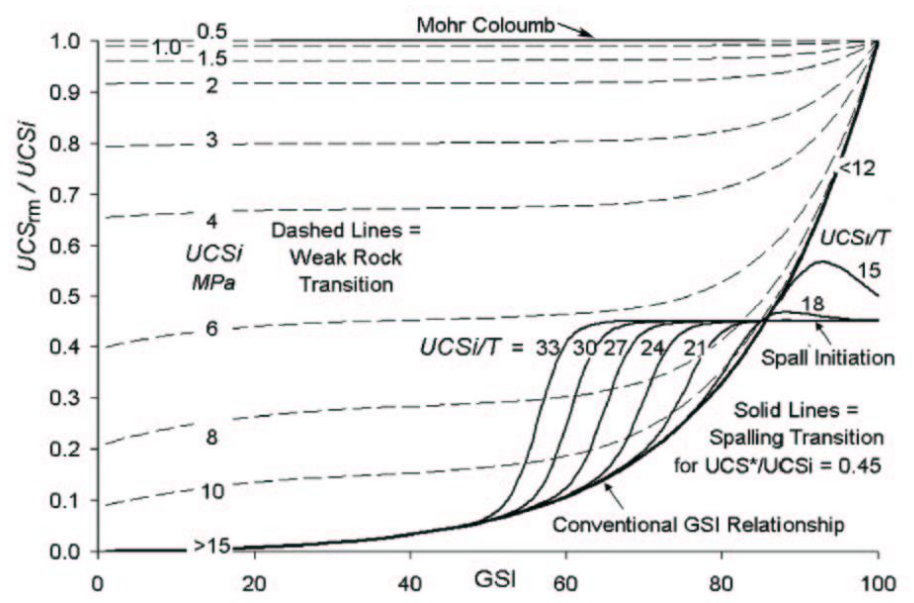

Figure 5 Normalised rock mass strength $\left(\mathrm{UCS}_{\mathrm{rm}} / \mathrm{USC}_{\mathrm{i}}\right)$ as a function of Geological Strength Index (GSI) showing the conventional Hoek-Brown relationship and "weak" and "strong" rock mass transition functions (Carter et al., 2008)

\subsection{Plasticity formulations}

As has been noted, the Hoek-Brown criterion was developed originally as a peak strength criterion for 'hard' intact rock and jointed rock masses. However, many of the computer codes used in carrying out stressdeformation analyses in rock engineering use elastoplastic constitutive models incorporating yield criteria based on the incremental theory of plasticity. An introduction to the use of yield criteria based on plasticity theory is given by Brady and Brown (2004). Whereas the Hoek-Brown criterion was formulated in terms of the major and minor principal stresses at peak strength, $\sigma_{1}$ and $\sigma_{3}$, plasticity-based yield criteria are usually expressed in terms of a yield function, $f\left(\mathrm{I}_{1}, \mathbf{J}_{2}\right)=0$, where $\mathrm{I}_{1}$ is the first invariant of the stress tensor, $I_{1}=\sigma_{1}+\sigma_{2}+\sigma_{3}$, and $J_{2}$ is the second invariant of the deviator stress tensor, $J_{2}=1 / 2\left(S_{1}^{2}+S_{2}^{2}+S_{3}^{2}\right)$, in which $S_{1}=\sigma_{1}-I_{1} / 3$ etc. Some yield criteria used for geological materials also involve the third invariant of the deviator stress tensor, $\mathrm{J}_{3}=\mathrm{S}_{1} \mathrm{~S}_{2} \mathrm{~S}_{3}$.

The Hoek-Brown criterion has been used as the basis for a number of yield criteria developed for rocks and rock masses (Pan and Hudson, 1988; Cundall et al., 2003; Priest, 2005; Yu, 2006; Benz et al., 2008; Clausen and Damkilde, 2008). In the simplest total stress form, the original and generalised criteria given by Equations (1) and (2) can be written as the yield function (Yu, 2006):

$$
f=\left\{\sigma_{1}-\sigma_{3}-\sigma_{\mathrm{ci}}\left[m_{b}\left(\sigma_{3}{ }^{\prime} / \sigma_{\mathrm{ci}}\right)+s\right]^{a}\right\}=0
$$

As well as a yield function describing the peak yield strength, the specification of a full constitutive model requires a set of elastic parameters, a plastic potential function, a dilatancy angle, post-peak stress-strain relations and a definition of residual strength. While most of the required parameters can be measured in carefully conducted tests on intact rock, particularly the weaker and less brittle rocks (Elliott and Brown, 1985), they cannot be measured directly for jointed rock masses and so have to be estimated. An approximate method of estimating the residual strengths of rock masses using the Hoek-Brown criterion and an estimated value of the GSI at the residual condition, GSIr, has been proposed by Cai et al. (2007). 
There is particular difficulty in estimating the dilation angle for the expected case of non-associated flow, and in representing the post-peak behaviour which, in the simplest of terms, may be regarded as being elastic-brittle in very good quality hard rock masses, strain softening in average quality rock masses, or elastic-perfectly plastic (with the peak and residual occurring at the same stress) in very poor quality soft rock masses. Hoek and Brown (1997) suggested that values of the dilation angle, $\psi$, of $\varphi / 4, \varphi / 8$ and 0 , may be appropriate in these three cases, respectively, where $\varphi$ is the equivalent Mohr-Coulomb friction angle at peak strength. Values such as these have been incorporated into analyses using the non-linear yield criterion and associated and non-associated flow laws (Serrano et al., 2005). The results show that value of $\psi$ can have a significant influence on the results obtained in stability analyses. Fundamental considerations and carefully analysed experimental results (Detournay, 1986; Crowder and Bawden, 2004; Alejano and Alonso, 2005) suggest that the post-peak dilatancy angles for rocks and rock masses are unlikely to be constants but to decrease with plastic strain following yield. This is an area that requires more detailed investigation. As suggested by Crowder and Bawden (2006), using high-quality field instrumentation data to calibrate numerical analyses provides a means of back-calculating the required rock mass parameters. Beck et al. (2006) provide another example of the application of this general approach.

Because the Hoek-Brown criterion in its original and extended forms is non-linear and a non-associated flow law is usually used, the incorporation of the full elasto-plastic constitutive model into numerical schemes for solving boundary value problems in rock engineering is not a straight-forward matter. Clausen and Damkilde (2008) provide a good account of how the difficulties involved may be resolved. Constitutive models incorporating various versions of the Hoek-Brown criterion have been incorporated into the finite difference scheme, FLAC3D (Cundall et al., 2003) and a number of finite element packages (Merifield et al., 2006; Clausen and Damkilde, 2008). A significant feature of these numerical codes is that they redistribute the stresses to obtain a new equilibrium position when yield occurs within the problem domain. However, as Cai (2008b) has demonstrated, the differing formulations of numerical codes can cause different post-peak stress paths to be followed and different results to be obtained.

\section{$5 \quad$ Estimating rock mass deformability}

A value of the deformation (or Young's) modulus of the rock mass is required when carrying out numerical stress analyses to determine the stresses and displacements induced in the rock mass when it is loaded or when the stresses are redistributed as a result of excavation. Clearly, like its strength, the in situ deformability of a rock mass will depend on the properties of both the intact rock and the discontinuities present within the rock mass. Experience shows that this deformability can be highly variable and difficult to measure or predict, despite the fact that a number of theoretical approaches, often using anisotropic elasticity models, have been made to the problem. There is now a 30 year history of attempts to correlate rock mass deformabilities with the major rock mass classifications.

Bieniawski (1978) compiled values of in situ deformation modulus determined using a range of test methods at 15 sites throughout the world. He found that for values of Rock Mass Rating (RMR) of greater than about 55 , the mean deformation modulus, $E_{M}$, measured in GPa could be approximated by the empirical equation:

$$
E_{M}=2(\mathrm{RMR})-100
$$

Serafim and Pereira (1983) found that an improved fit to their own and to Bieniawski's data, particularly in the range of $E_{M}$ between 1 and $10 \mathrm{GPa}$, was given by the relation:

$$
E_{M}=10^{(\mathrm{RMR}-10) / 40}
$$

Barton (2002) added further data and fitted the equation:

$$
E_{M}=10 \mathrm{Q}^{1 / 3}
$$

where $\mathrm{Q}_{\mathrm{c}}=\mathrm{Q} \sigma_{\mathrm{c}} / 100$.

Following Hoek and Brown (1997), Hoek et al. (2002) proposed the more complex empirical relation:

$$
E_{M}=(1-D / 2) \sqrt{ }\left(\sigma_{\mathrm{c} i} / 100\right) \cdot 10^{((\mathrm{GSI}-10) / 40)}
$$

which is derived from Equation (17) but gives an improved fit to the data at lower values of GSI, and includes the factor $D$ to allow for the effects of blast damage and stress relaxation. Finally, more recently, 
Hoek and Diederichs (2006) were able to obtain improved fits to a wider range of data by using the sigmoidal relation:

$$
E_{M}=E_{i}\left(0.02+\frac{1-D / 2}{1+e^{((60+15 D-G S I) / 11)}}\right)
$$

where $E_{i}$ is the modulus of the intact rock. In the absence of measured values, $E_{i}$ may be estimated from the relation:

$$
E_{i}=(M R) \sigma_{\mathrm{ci}}
$$

where $\sigma_{\mathrm{ci}}$ is the uniaxial compressive strength of the intact rock and $M R$ is the modulus ratio introduced by Deere (1968) and updated by Hoek and Diederichs (2006). $M R$ varies with rock type and texture.

The author now uses Equation (20) routinely in estimating the in situ deformabilities of rock masses in dam foundations (Marley et al., 2007; Brown and Marley, 2008) and other projects. As well as the better fit to known data that it gives, this method has the great advantage that, because of the shape of the sigmoidal curve used, it avoids the unrealistically high values of $E_{M}$ given by the other methods as RMR or GSI $\rightarrow 100$. It will be noted that, as well as $E_{i}$ and the GSI, Equation (20) contains the disturbance factor, $D$. Great care must be exercised in selecting values of $D$ for use in estimating foundation rock mass deformabilities. If the overlying soil and weathered rock are removed by ripping, for example, the extent of disturbance in all but the top metre or so of rock can be expected to be minimal. If blasting is used, the disturbance might be expected to extend to a depth of a few metres. For one dam foundation, the author used values of $D$ of 0.5 for the top two metres of exposed rock, 0.2 for the next three metres, and zero for the remainder of the foundation. In this case, for a meta-siltstone with an average GSI of $57, \sigma_{\mathrm{ci}}=38 \mathrm{MPa}$, and $E_{i}=35 \mathrm{GPa}$, estimated values of $E_{M}$ of 16,12 and $8 \mathrm{GPa}$ were obtained for values of $D$ of $0,0.2$ and 0.5 , respectively. The author suspects that, in some applications, apparently low values of rock mass modulus have been obtained as a result of using values of $D$ which are too high. He also considers that correlations of $E_{M}$ with GSI (or any other rock mass classification system) are unlikely to be reliable for values of GSI of less than about 30 .

It must be recognised that Equations (16) to (20) relate rock mass classification indices to measured static deformability values that show considerable scatter. Accordingly, it cannot be expected that they will always provide accurate estimates of $E_{M}$. In the not unexpected cases in which measured or back-calculated values of $E_{M}$ differ from the predictions of Equation (20), sometimes by a considerable margin (Read and Richards, 2007; Pells, 2008), differences or errors can arise from the determination of the GSI, the application of the equation to low values of GSI, the selection of the value of the parameter, $D$, measurement error, the assumptions made and methods used to back-calculate values, as well as from natural variability of the rock mass so that, on occasion, we may not be comparing like with like. It must also be remembered that rock mass moduli can be expected to be highly anisotropic. They also vary non-linearly with the level of applied stress, and so can be expected to vary with depth. Because of the high costs of carrying out in situ deformability tests, geophysical methods are often used to estimate in situ moduli. These methods generally involve studies of the transmission of elastic compression and shear waves through the rock mass and empirical correlations with rock mass classifications and dynamic and/or static moduli which are unlikely to be more reliable than Equation (20) or similar expressions.

\section{Modelling rock mass behaviour using advanced numerical methods}

When the predecessors of the current generation of numerical methods and codes were first developed and applied in rock mechanics studies, they offered little hope of being able to model the detailed responses of rock and rock mass samples to changes in applied stress and so replace the laboratory and field tests, and empirical methods, that were then being used to estimate the rock and rock mass properties required for use in numerical or other analyses of rock engineering problems. However, with the greatly improved efficiencies of current numerical schemes and the increased computing power now available, there are indications that fundamentally-based, numerically-intensive approaches are now able to model the engineering responses of rock and rock masses using some basic measured properties of the rock and the rock mass geometry as inputs. Two of these approaches will be outlined here to provide an indication of their bases and potential. 
The first of these approaches is the synthetic rock mass (SRM) model for jointed rock (Mas Ivars et al., 2007; Pierce et al., 2007). In this approach, 3D SRM samples simulate the intact rock as an assembly of bonded spheres using the particle flow code, $\mathrm{PFC}^{3 \mathrm{D}}$ (Potyondy and Cundall, 2004). The rock mass geometry is represented as an embedded discrete network of disc-shaped fractures (joints) derived from a stochastic discrete fracture network (DFN) simulation (Dershowitz, 1995; Rogers et al., 2007). The main inputs required are in situ rock mass geometry characterisation data for use in the DFN simulations, and intact rock properties ( $\sigma_{\mathrm{ci}}, \mathrm{E}_{\mathrm{i}}$ and Poisson's ratio) and joint stiffnesses and shear strengths for use in calibration of the bonded particle modelling. The outputs are rock mass properties that may be employed in empirical, numerical or analytical methods of analysis.

The SRM methodology employs a sliding joint model that allows large rock volumes containing thousands of joints to be simulated rapidly. Samples may be subjected to any desired stress path. The onset of damage, identified by the breakage of inter-particle bonds, occurs well before the peak strength is reached. As illustrated by Figure 6, the results may be fitted to the model of brittle fracture discussed in Section 3.2. (Note that, in Figure 6, the major and minor principal stresses are represented by Sigma 1 or s1 and Sigma 3 or s3, respectively.) Of particular interest is the ability to obtain predictions of the 'brittleness' of SRM samples by tracking plastic shear strains relative to the reducing cohesion as the samples soften from their peak to their residual strengths (Mas Ivars et al., 2007; Pierce et al., 2007).

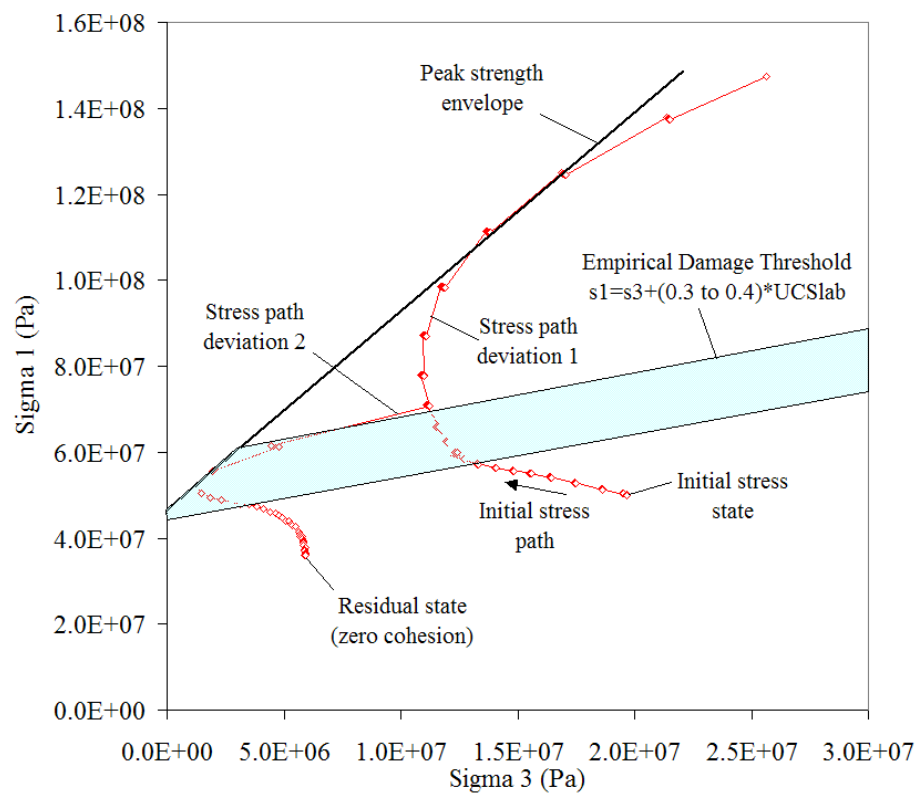

Figure 6 Stress paths, fitted peak strength envelope and damage threshold observed in a SRM sample (Mas Ivars et al., 2007; Pierce et al., 2007)

The SRM approach has been used in both fundamental and applied studies of the complex processes involved in caving propagation and rock fragmentation in block and panel caving. The validity of the approach has been demonstrated by Reyes-Montes et al. (2007) through the good correlation found between the fracturing modes and orientations predicted by the model and those observed from recorded microseismicity for five geotechnical domains in the Northparkes E26 Mine, Lift 2, Australia.

The second of these numerically-intensive approaches described by Pine et al. (2006; 2007), is also based on a stochastic DFN model of the rock mass geometry, but uses the finite element-discrete element code, ELFEN (Owen et al., 2004), to model the fracturing process in the rock material such that the initial finite element continuum can fracture into discrete blocks. The method of modelling discrete fracturing under tensile and compressive stress fields is based on a Mohr-Coulomb failure surface in compression, and three independent anisotropic rotating crack models in tension. Extension fracturing is modelled by coupling the softening of the anisotropic rotating crack failure criterion to the evolution of compressive plastic strain. An explicitly time-integrated coupled discrete element-finite element approach is employed with an explicit Lagrangian contact algorithm to enforce non-penetration of the surfaces created when the tensile strength is 
depleted (Pine et al., 2007). Like the SRM model, this approach provides an insight into the complex failure mechanisms involved in rock masses in a range of engineering applications, including block and panel caving (Ford et al., 2007), and provides a direct method of estimating rock mass strengths and deformabilities. However, it is important to note that the effectiveness of both approaches in practice depends on the quantity and quality of the rock mass geometry data that provide inputs to the DFN model (Pine et al., 2007).

\section{Conclusions}

The Hoek-Brown empirical strength criterion was developed about 30 years ago as a means of making approximate estimates of the peak strengths of "hard" rock masses for use in preliminary studies of rock engineering projects for which only limited ranges of site characterisation and test data were available. As time went by, the criterion was modified in a number of ways and became incorporated into more sophisticated methods of analysis. Some of the extensions and applications are considered to have extended the criterion beyond its originally intended limits and purposes. From the outset, problems to which the isotropic criterion was considered not to be applicable were identified and were reiterated with the publication of subsequent versions of the criterion. In parallel with the peak strength criterion, a series of correlations of rock mass deformabilities with rock mass classification schemes were developed by others. An important development occurred in the mid 1990s when, recognising the weaknesses of the existing rock mass classification schemes for use in estimating the mechanical properties of rock masses, Hoek (1994) developed a new, purpose-built rock mass classification scheme, the geological strength index (GSI), that was used in subsequent versions of the empirical strength criterion and in associated methods of estimating rock mass deformability.

It should always be borne in mind that the Hoek-Brown criterion and its derivatives are empirical methods of estimating rock mass properties. They are not intended to replace and, indeed, depend for their successful application on, careful thought, detailed appraisals of site geology, carefully conducted site characterisation and laboratory test programs, and a detailed evaluation of the mechanics of the engineering problem being addressed. They should not be treated as 'black-box' or 'cook-book' approaches. The author has the impression that not all practitioners follow sound geotechnical engineering processes in seeking to apply the criterion. In some cases, tables of values of $m_{i}$ are used in final design without the required testing being carried out. In others, insufficient thought and care are given to the selection of parameters such as the disturbance factor, $D$, and the range of minor principal stresses for which both Hoek-Brown and equivalent Mohr-Coulomb parameters are determined.

Although the developments outlined in this paper have been roundly criticised from time-to-time, the extent of their adaptation and use (including their possible over-use) in engineering practice suggest that something like them was, and remains, badly needed. However, as indicated clearly above, they are empirical methods, not that empirical methods haven't been used with considerable success throughout the history of engineering, including geotechnical engineering. Ideally, a more fundamentally-based approach that explicitly accounts for the factors that influence the mechanical responses of rocks and rock masses is required. As do some others (Read, 2007), the author considers that the advanced numerically-intensive approaches outlined in Section 6 have the potential to meet this need and represent a most promising way forward. Until those methods, or others like them, have been developed to the stage at which they can be used in advanced, if not routine, engineering practice, it is likely that there will remain a place for empirical methods of estimating the mechanical properties of rock masses.

\section{Acknowledgements}

The author wishes to acknowledge the immense contributions made by Dr Evert Hoek to the development of the main approaches to estimating rock mass strength and deformability outlined in this paper, and to thank Dr Hoek for having given him the opportunity to become involved in this undertaking. The author would like to dedicate this paper to the memory of the late Dr Antonio Karzulovic with whom he discussed the proposed contents of the paper shortly before Dr Karzulovic's untimely death in Brisbane on 13 March 2008. Finally, the author wishes to thank Dr Hoek and Dr Trevor Carter for providing him with information used in this paper, and the management and staff of Golder Associates Pty Ltd, Brisbane, for their assistance with the paper's preparation. 


\section{References}

Alejano, L.R. and Alonso, E. (2005) Considerations of the dilatancy angle in rocks and rock masses. International Journal of Rock Mechanics and Mining Sciences, 42(4), pp. 481-507.

Alemdag, S., Gurocak, Z., Solanki, P. and Zaman, M. (2008) Estimation of bearing capacity of basalts at the Atasu dam site, Turkey. Bulletin of Engineering Geology and the Environment, 67(1), pp. 79-85.

Amadei, B. (1988) Strength of a regularly jointed rock mass under biaxial and axisymmetric loading conditions. International Journal of Rock Mechanics and Mining Sciences, 25(1), pp. 3-13.

Barton, N. (2002) Some new Q-value correlations to assist in site characterisation and tunnel design. International Journal of Rock Mechanics and Mining Sciences, 39(2), pp. 185-216.

Barton, N., Lein, R. and Lunde, J. (1974) Engineering classification of rock masses for design of tunnel support. Rock Mechanics, 6(4), pp. 189-236.

Beck, D., Reusch, F., Arndt, S., Thin, I., Stone, C., Heap, M. and Tyler, D. (2006) Numerical modelling of seismogenic development during cave initiation, propagation and breakthrough. Deep and High Stress Mining 2006, Hassani (editor), Balkema, Rotterdam, pp. 405-414.

Benz, T., Schwab, R., Kauther, R.A. and Vermeer, P.A. (2008) A Hoek-Brown criterion with intrinsic material strength factorization. International Journal of Rock Mechanics and Mining Sciences, 45(2), pp. 210-222.

Bieniawski, Z.T. (1976) Rock mass classification in rock engineering. Exploration for Rock Engineering, Proceedings Symposium on Exploration, Bieniawski (editor), Balkema, Cape Town, 1, pp. 97-106.

Bieniawski, Z.T. (1978) Determining rock mass deformability: experience from case histories. International Journal of Rock Mechanics and Mining Sciences, 15(5), pp. 237-247.

Brady, B.H.G. and Brown, E.T. (2004) Rock Mechanics for Underground Mining, 3rd edition. Kluwer, Dordrecht, $628 \mathrm{p}$.

Brown, E.T. (1970) Strength of models of rock with intermittent joints. Journal of the Soil Mechanics and Foundations Division, ASCE, 96(SM6), pp. 1935-1949.

Brown, E.T. (1984) The stress-strain behaviour of jointed rock masses. Proceedings 6th National Rock Mechanics Symposium, Wittke (editor), Geotechnik Special Issue, pp. 13-20.

Brown, E.T. (2004) The mechanics of discontinua: engineering in discontinuous rock. Proceedings 9th Australia New Zealand Conference on Geomechanics. Farquar, Kelsy, Marsh and Fellows (editors), New Zealand Geotechnical Society, Auckland, 1, pp. 51-72.

Brown, E.T. (2007) Fifth Müller Lecture. Rock mechanics - the basic mining science: challenges in underground mass mining. Proceedings 11th Congress of the International Society for Rock Mechanics, Ribeiro e Sousa, Ollala and Grossmann (editors), Taylor and Francis, Leiden, 3, pp. 1335-1346.

Brown, E.T. and Marley, M. (2008) Estimating rock mass properties for stability analyses of new and existing dams. Proceedings International Symposium on Operation, Rehabilitation and Up-grading of Dams, 76th Annual Meeting of ICOLD (in press).

Brown, E.T. and Trollope, D.H. (1970) Strength of a model of jointed rock. Journal of the Soil Mechanics and Foundations Division, ASCE, 96(SM2), pp. 685-704.

Cai, M. (2008a) Influence of intermediate principal stress on rock fracturing and strength near excavation boundaries insight from numerical modelling. International Journal of Rock Mechanics and Mining Sciences, 45(5), pp. 763-772.

Cai, M. (2008b) Influence of stress path on tunnel excavation response - numerical tool selection and modelling strategy. Tunnelling and Underground Space Technology, 23 (in press).

Cai, M., Kaiser, P.K., Tasaka, Y. and Minami, M. (2007) Determination of residual strength parameters of jointed rock masses using the GSI system. International Journal of Rock Mechanics and Mining Sciences, 44(2), pp. 247-265.

Cai, M., Kaiser, P.K., Tasaka, Y., Maejima, T., Morioka, H. and Minami, M. (2004a) Generalised crack initiation and crack damage stress thresholds of brittle rock masses near underground excavations. International Journal of Rock Mechanics and Mining Sciences, 41(5), pp. 833-847.

Cai, M., Kaiser, P.K., Uno, H., Tasaka, Y. and Minami, M. (2004b) Estimation of rock mass strength and deformation modulus of jointed hard rock masses using the GSI system. International Journal of Rock Mechanics and Mining Sciences, 41(1), pp. 3-19.

Carranza-Torres, C. (2004) Some comments on the application of the Hoek-Brown failure criterion for intact rock and for rock masses to the solution of tunnel and slope excavation problems. Proceedings, MIR 2004 - X Conference on Rock and Engineering Mechanics, Barla and Barla (editors), Pàtron Editore, Bologna, pp. 285-326.

Carranza-Torres, C. and Fairhurst, C. (1999) The elasto-plastic response of underground excavations in rock masses that satisfy the Hoek-Brown failure criterion. International Journal of Rock Mechanics and Mining Sciences, 36(6), pp. 777-809. 
Carter, T.G., Diederichs, M.S. and Carvalho, J.L. (2007) A unified procedure for prediction of strength and post yield behaviour for rockmasses at the extreme ends of the rock competency scale. Proceedings 11th Congress of the International Society for Rock Mechanics, Ribeiro e Sousa, Olalla and Grossmann (editors), Taylor and Francis, Leiden, 1, pp. 161-164.

Carter, T.G., Diederichs, M.S. and Carvalho, J.L. (2008) Application of modified Hoek-Brown transition relationships for assessing strength and post yield behaviour at both ends of the rock competence scale. Proceedings 6th International Symposium on Ground Support in Mining and Civil Engineering Construction, Stacey and Malan (editors), SAIMM, Johannesburg, pp. 37-60.

Carvalho, J.L., Carter, T.G. and Diederichs, M.S. (2007) An approach for prediction of strength and post-yield behaviour for rock masses of low intact strength. Rock Mechanics: Meeting Society's Challenges and Demands, Proceedings 1st Canada - U.S. Rock Mechanics Symposium, Eberhardt, Stead and Morrison (editors), Taylor and Francis, Leiden, 1, pp. 249-257.

Clausen, J. and Damkilde, L. (2008) An exact implementation of the Hoek-Brown criterion for elasto-plastic finite element calculations. International Journal of Rock Mechanics and Mining Sciences, 45 (6), pp. 831-847.

Cook, N.G.W. (1965) The failure of rock. International Journal of Rock Mechanics and Mining Sciences, 2(4), pp. 389-403.

Crowder, J.J. and Bawden, W.F. (2004) Review of post-peak parameters and behaviour of rock masses: current trends and research. Rocnews, Fall, 2004, 14 p., viewed on 15 May 2008, <http://www.rocscience.com/library/rocnews/Fall2004.htm>.

Crowder, J.J. and Bawden, W.F. (2006) The estimation of post-peak rock mass properties: numerical back analysis calibrated using in situ instrumentation data. Rocnews, Winter 2006, 32 p., viewed on 15 May 2008, $<$ http://www.rocscience.com/library/rocnews/winter2006.htm>.

Cundall, P., Carranza-Torres, C. and Hart, R. (2003) A new constitutive model based on the Hoek-Brown criterion. FLAC and Numerical Modeling in Geomechanics 2003, Proceedings 3rd International FLAC Symposium, Brummer, Andrieux, Detournay and Hart (editors), Balkema, Lisse, pp. 17-25.

Deere, D.U. (1968) Geological considerations. Rock Mechanics in Engineering Practice, Stagg and Zienkiewicz (editors), John Wiley, London, pp. 1-20.

Dershowitz, W. (1995) Interpretation and synthesis of discrete fracture orientation, size, shape, spatial structure and hydrologic data by forward modeling. Fractured and Jointed Rock Masses, Myer, Cook, Goodman and Tsang (editors), Balkema, Rotterdam, pp. 579-586.

Detournay, E. (1986) Elastoplastic model of a deep tunnel for a rock with variable dilatancy. Rock Mechanics and Rock Engineering, 19(2), pp. 99-108.

Diederichs, M.S., Kaiser, P.K. and Eberhardt, E. (2004) Damage initiation and propagation in hard rock during tunnelling and the influence of near-face stress rotation. International Journal of Rock Mechanics and Mining Sciences, 41(5), pp. 785-812.

Diederichs, M.S., Carvalho, J.L. and Carter, T.G. (2007) A modified approach for prediction of strength and post-yield behaviour for high GSI rock masses in strong, brittle rock. Rock Mechanics: Meeting Society's Challenges and Demands, Proceedings 1st Canada - U.S. Rock Mechanics Symposium, Eberhardt, Stead and Morrison (editors), Taylor and Francis, Leiden, 1, pp. 277-285.

Douglas, K.J. and Mostyn, G. (2004) The shear strength of rock masses. Proceedings 9th Australia New Zealand Conference on Geomechanics, Farquar, Kelsy, Marsh and Fellows (editors), New Zealand Geotechnical Society, Auckland, 1, pp. 166-172.

Elliott, G.M. and Brown, E.T. (1985) Yield of a soft, high porosity rock. Géotechnique, 35(4), pp. 413-423.

Fell, R., MacGregor, P., Stapledon, D. and Bell, G. (2005) Geotechnical Engineering of Dams. Balkema, Leiden, 912 p.

Ford, N.T., Pine, R.J. and Flynn, Z.N. (2007) Discrete fracture network modelling and characterisation of rock masses for block caving design. Proceedings 11 th Congress of the International Society for Rock Mechanics, Ribeiro e Sousa, Ollala and Grossmann (editors), Taylor and Francis, Leiden, 1, pp. 231-236.

Hoek, E. (1968) Brittle failure of rock. Rock Mechanics in Engineering Practice, Stagg and Zienkiewicz (editors), Wiley, London, pp. 99-124.

Hoek, E. (1983) Strength of jointed rock masses. Géotechnique, 33(3), pp. 187-223.

Hoek, E. (1994) Strength of rock and rock masses. ISRM News Journal, 2(2), pp. 4-16.

Hoek, E. (2007) Rock mass properties. Practical Rock Engineering, viewed on 15 May 2008, <http://www.rocscience.com/hoek/pdf/11_Rock_mass_properties.pdf>.

Hoek, E. and Brown, E.T. (1980a) Underground Excavations in Rock. Institution of Mining and Metallurgy, London, $527 \mathrm{p}$.

Hoek, E. and Brown, E.T. (1980b) Empirical strength criterion for rock masses. Journal of the Geotechnical Engineering Division, ASCE, 106(GT9), pp. 1013-1035.

Hoek, E. and Brown, E.T. (1988) The Hoek-Brown failure criterion - a 1988 update. Rock Engineering for Underground Excavations, Proceedings 15th Canadian Rock Mechanics Symposium, Curran (editor), Department of Civil Engineering, University of Toronto, Toronto, pp. 31-38. 
Hoek, E. and Brown, E.T. (1997) Practical estimates of rock mass strength. International Journal of Rock Mechanics and Mining Sciences, 34(8), pp. 1165-1186.

Hoek, E., Carranza-Torres, C. and Corkum, B. (2002) Hoek-Brown failure criterion - 2002 edition. Mining and Tunnelling Innovation and Opportunity, Proceedings 5th North American Rock Mechanics Symposium and 17th Tunnelling Association of Canada Conference, Hammah, Bawden, Curran and Telesnicki (editors), University of Toronto, Toronto, 1, pp. 267-273.

Hoek, E. and Diederichs, M.S. (2006) Empirical estimation of rock mass modulus. International Journal of Rock Mechanics and Mining Sciences, 43(2), pp. 203-215.

Hoek, E., Kaiser, P.K. and Bawden, W.F. (1995) Support of Underground Excavations in Hard Rock. Balkema, Rotterdam, $215 \mathrm{p}$.

Hoek, E. and Karzulovic, A. (2000) Rock-mass properties for surface mines. Slope Stability for Surface Mining, Hustrulid, McCarter and Van Zyl (editors), SME, Littleton, pp. 59-69.

Hoek, E. and Marinos, P. (2007) A brief history of the development of the Hoek-Brown failure criterion. Soils and Rocks, No 2, November.

Hoek, E., Marinos, P. and Benissi, M. (1998) Applicability of the Geological Strength Index (GSI) classification for very weak and sheared rock masses. The case of the Athens schist formation. Bulletin of Engineering Geology and the Environment, 57(2), pp. 151-160.

Hoek, E., Wood, D. and Shah, S. (1992) A modified Hoek-Brown criterion for jointed rock masses. Rock Characterization, Proceedings ISRM Symposium, Eurock '92, Hudson (editor), British Geotechnical Society, London, pp. 209-214.

Jaeger, J.C. (1960) Shear failure of anisotropic rocks. Geological Magazine, 97, pp. 65-72.

Jaeger, J.C. (1970) Behavior of closely jointed rock. Rock Mechanics - Theory and Practice, Proceedings 11 th Symposium on Rock Mechanics, Somerton (editor), AIME, New York, pp. 57-68.

Jaeger, J.C. and Cook, N.G.W. (1969) Fundamentals of Rock Mechanics. Methuen, London, 513 p.

John, K.W. (1962) An approach to rock mechanics. Journal of the Soil Mechanics and Foundations Division, ASCE, 88(SM4), pp. 1-30.

John, K.W. (1970) Civil engineering approach to evaluate strength and deformability of regularly jointed rock. Rock Mechanics - Theory and Practice, Proceedings 11th Symposium on Rock Mechanics, Somerton (editor), AIME, New York, pp. 69-80.

Johnston, I.W. and Chiu, H.K. (1984) Strength of weathered Melbourne mudstone. Journal of Geotechnical Engineering, ASCE, 110(7), pp. 875-898.

Kaiser, P.K. (2006) Rock mechanics considerations for construction of deep tunnels in brittle rock. Rock Mechanics in Underground Construction, Proceedings 4th Asian Rock Mechanics Symposium, Leung and Zhou (editors), World Scientific Publishing Company, Singapore, pp. 47-58.

Kaiser, P.K., Diederichs, M.S., Martin, C.D., Sharp, J. and Steiner, W. (2000) Underground works in hard rock tunnelling and mining. Proceedings GeoEng 2000, Technomic Publishing Company, Lancaster, Pennsylvania, 1, pp. 841-926.

Ladanyi, B. and Archambault, G. (1970) Simulation of shear behaviour of a jointed rock mass. Rock Mechanics Theory and Practice, Proceedings 11th Symposium on Rock Mechanics, Somerton (editor), AIME, New York, pp. 105-125.

Li, A.J., Merifield, R.S. and Lyamin, A.V. (2008) Stability charts for rock slopes based on the Hoek-Brown failure criterion. International Journal of Rock Mechanics and Mining Sciences, 45(5), pp. 689-700.

Londe, P. (1988) Discussion on "Determination of shear failure envelope in rock masses" by R. Ucar. Journal of the Geotechnical Engineering Division, ASCE, 114(3), pp. 374-376.

Maghous, S., Bernaud, D., Fréard, J. and Garnier, D. (2008) Elastoplastic behaviour of jointed rock masses as homogenized media and finite element analysis. International Journal of Rock Mechanics and Mining Sciences, 45 (in press).

Marinos, P. and Hoek, E. (2001) Estimating the geotechnical properties of heterogeneous rock masses such as flysch. Bulletin of Engineering Geology and the Environment, 60(2), pp. 85-92.

Marinos, P., Hoek, E. and Marinos, V. (2006) Variability of the engineering properties of rock masses quantified by the geological strength index: the case of ophiolites with special emphasis on tunnelling. Bulletin of Engineering Geology and the Environment, 65(2), pp. 129-142.

Marinos, P., Marinos, V. and Hoek, E. (2007) The Geological Strength Index (GSI): a characterization tool for assessing engineering properties for rock masses. Proceedings International Workshop on Rock Mass Classification for Underground Mining, Mark, Pakalnis and Tuchman (editors), Information Circular 9498, NIOSH, Pittsburgh, pp. 87-94.

Marley, M., Dryden, G., Eades, G., Brown, E. and Huftile, G. (2007) The geotectonics and geotechnics of the Traveston Crossing Dam foundation. Dams - Securing Water for Our Future, Proceedings NZSOLD ANCOLD 2007 Conference, McSaveney (editor), IPENZ Proceedings of Technical Groups, 33(1LD), pp. 309-318. 
Martin, C.D. (1997) Seventeenth Canadian Geotechnical Colloquium: the effect of cohesion loss and stress path on brittle rock strength. Canadian Geotechnical Journal, 34(5), pp. 698-725.

Martin, C.D., Kaiser, P.K. and McCreath, D.R. (1999) Hoek-Brown parameters for predicting the depth of brittle failure around tunnels. Canadian Geotechnical Journal, 36(1), pp. 136-151.

Mas Ivars, D., Deisman, N., Pierce, M. and Fairhurst, C. (2007) The Synthetic Rock Mass approach - a step forward in the characterization of jointed rock masses. Proceedings 11th Congress of the International Society for Rock Mechanics, Ribeiro e Sousa, Ollala and Grossmann (editors), Taylor and Francis, Leiden, 1, pp. 485-490.

Medhurst, T.P. and Brown, E.T. (1998) A study of the mechanical behaviour of coal for pillar design. International Journal of Rock Mechanics and Mining Sciences, 35(8), pp. 1087-1105.

Merifield, R.S., Lyamin, A.V. and Sloan, S.W. (2006) Limit analysis solutions for the bearing capacity of rock masses using the generalised Hoek-Brown criterion. International Journal of Rock Mechanics and Mining Sciences, 43(6), pp. 920-937.

Mostyn, G. and Douglas, K. (2000) Strength of intact rock and rock masses. Proceedings GeoEng 2000, Technomic Publishing Company, Lancaster, Pennsylvania, 1, pp. 1389-1421.

Müller, L. (1964) Application of rock mechanics in the design of rock slopes. State of Stress in the Earth's Crust, Judd (editor), American Elsevier, New York, pp. 575-598.

Owen, D.R.J., Feng, Y.T., de Souza Neto, E.A., Cottrell, M.G., Wang, F., Andrade Pires, F.M. and Yu, J. (2004) The modelling of multi-fracturing solids and particulate media. International Journal of Numerical Methods in Engineering, 60(1), pp. 317-340.

Pan, X.D. and Hudson, J.A. (1988) A simplified three-dimensional Hoek-Brown yield criterion. Rock Mechanics and Power Plants, Romana (editor), Balkema, Rotterdam, 1, pp. 95-103.

Pells, P.J.N. (2008) What happened to the mechanics in rock mechanics and the geology in engineering geology? Proceedings 6th International Symposium on Ground Support in Mining and Civil Engineering Construction, Stacey and Malan (editors), SAIMM, Johannesburg, pp. 1-36.

Pierce, M., Cundall, P., Potyondy, D. and Mas Ivars, D. (2007) A synthetic rock mass model for jointed rock. Rock Mechanics: Meeting Society's Challenges and Demands, Proceedings 1st Canada - U.S. Rock Mechanics Symposium, Eberhardt, Stead and Morrison (editors), Taylor and Francis, Leiden, 1, pp. 341-349.

Pine, R.J., Coggan, J.S., Flynn, Z.N. and Elmo, D. (2006) The development of a new numerical modelling approach for naturally fractured rock masses. Rock Mechanics and Rock Engineering, 39(5), pp. 395-419.

Pine, R.J., Owen, D.R.J., Coggan, J.S. and Rance, J.M. (2007) A new discrete fracture modelling approach for rock masses. Géotechnique, 57(9), pp. 757-766.

Potyondy, D.O. and Cundall, P.A. (2004) A bonded-particle model for rock. International Journal of Rock Mechanics and Mining Sciences, 41(8), pp. 1329-1364.

Priest, S.D. (2005) Determination of shear strength and three-dimensional yield strength for the Hoek-Brown criterion. Rock Mechanics and Rock Engineering, 38(4), pp. 299-327.

Priest, S.D. and Brown, E.T. (1983) Probabilistic stability analysis of variable rock slopes. Transactions of the Institution of Mining and Metallurgy (Section A: Mining Industry), 92, January, pp. A1-12.

Read, J.R.L. (2007) Rock slope stability research. Slope Stability 2007, Proceedings 2007 International Symposium on Rock Slope Stability in Open Pit Mining and Civil Engineering, Potvin (editor), Australian Centre for Geomechanics, Perth, pp. 355-359.

Read, S. and Richards, L. (2007) Design inputs for stability assessment of dams on New Zealand greywackes. Dams Securing Water for Our Future, Proceedings NZSOLD ANCOLD 2007 Conference, McSaveney (editor), IPENZ Proceedings of Technical Groups, 33(1LD), pp. 319-329.

Reik, G. and Zacas, M. (1978) Strength and deformation characteristics of jointed media in true triaxial compression. International Journal of Rock Mechanics and Mining Sciences, 15(6), pp. 295-303.

Reyes-Montes, J.M., Pettitt, W.S. and Young, R.P. (2007) Validation of a Synthetic Rock Mass model using excavation induced seismicity. Rock Mechanics: Meeting Society's Challenges and Demands, Proceedings 1st Canada U.S. Rock Mechanics Symposium, Eberhardt, Stead and Morrison (editors), Taylor and Francis, Leiden, 1, pp. 365-369.

Rocscience. (2007) RocLab v 1.0, viewed on 15 May 2008, <http://www.rocscience.com/products/roclab.asp>.

Rogers, S.F., Kennard, D.K., Dershowitz, W.S. and van As, A. (2007) Characterising the in situ fragmentation of a fractured rock mass using a discrete fracture network approach. Rock Mechanics: Meeting Society's Challenges and Demands, Proceedings 1st Canada - U.S. Rock Mechanics Symposium, Eberhardt, Stead and Morrison (editors), Taylor and Francis, Leiden, 1, pp. 131-142.

Saroglou, H. and Tsiambaos, G. (2008) A modified Hoek-Brown failure criterion for anisotropic intact rock. International Journal of Rock Mechanics and Mining Sciences, 45(2), pp. 223-234.

Serafim, J.L. and Periera, J.P. (1983) Considerations of the geomechanical classification of Bieniawski. Proceedings International Symposium on Engineering Geology and Underground Construction, SPG/LNEC, Lisbon, 1, pp. II.33-42. 
Serrano, A., Estaire, J. and Olalla, C. (2007) Extension of the Hoek-Brown failure criterion to three dimensions. Proceedings 11th Congress of the International Society for Rock Mechanics, Ribeiro e Sousa, Ollala and Grossmann (editors), Taylor and Francis, Leiden, 1, pp. 289-292.

Serrano, A., Olalla, C. and González, J. (2000) Ultimate bearing capacity of rock masses based on the modified HoekBrown criterion. International Journal of Rock Mechanics and Mining Sciences, 37(6), pp. 1013-1018.

Serrano, A., Olalla, C. and Manzanas, J. (2005) Stability of highly fractured infinite rock slopes with nonlinear failure criteria and nonassociated flow laws. Canadian Geotechnical Journal, 42(2), pp. 393-411.

Trollope, D.H. (1968) The mechanics of discontinua or clastic mechanics in rock problems. Rock Mechanics in Engineering Practice, Stagg and Zienkiewicz (editors), Wiley, London, pp. 275-320.

Ucar, R. (1986) Determination of shear failure envelope in rock masses. Journal of Geotechnical Engineering, ASCE, 112(3), pp. 303-315.

Wawersik, W.R. and Fairhurst, C. (1970) A study of brittle rock fracture in laboratory compression experiments. International Journal of Rock Mechanics and Mining Sciences, 7(5), pp. 561-575.

Yoshinaka, R., Osada, M., Park, H., Tasaki, T. and Sasaki, K. (2008) Practical determination of mechanical design parameters of intact rock considering scale effect. Engineering Geology, 96(3-4), pp. 173-186.

Yu, H-S. (2006) Plasticity and Geotechnics. Springer, New York, 522 p.

Zuo, J-P., Li, H-T., Xie, H-P., Ju, Y. and Peng, S-P. (2008) A nonlinear strength criterion for rock-like materials based on fracture mechanics. International Journal of Rock Mechanics and Mining Sciences, 45(5), pp. 594-599. 